\title{
DOSE DEPENDENT EFFECT OF GLYCYRRHIZIN ON GLYCAEMIC CONTROL OF TYPE 2 DIABETIC RATS
}

\section{Mufakhara Fatimah ${ }^{1,2 \bowtie}$,Mahwash Malik',3, Sidra Mushtaq ${ }^{1,4}$, Javeria Sarfraz ${ }^{1,5}$, Zobia Mushtaq, ${ }^{1,6}$, Sadia Chiragh ${ }^{1,7}$}

\begin{abstract}
OBJECTIVE: To assess the effect of low and high dose of glycyrrhizin on body weight, fasting blood sugar level (FBSL), serum insulin and glycemic indices in high fat diet induced type 2 diabetic rats.

METHODS: In this experimental study with intervention period of 34 weeks, rats were grouped into four experimental groups; Group-A: normal control; Group-B: diabetic control; Group-C: glycyrrhizin-I50 and Group-D: glycyrrhizin-300. Diabetes mellitus was induced in rats by giving high fat diet with injection dexamethasone. At 32 weeks, body weight, FBSL, serum insulin, Homeostatic Model Assessment of Insulin Resistance (HOMA-IR), Homeostatic Model Assessment of beta cells (HOMA- $\beta$ ) and Quantitative Insulin Sensitivity Check Index (QUICKI) were estimated. Two experimental groups received glycyrrhizin $150 \mathrm{mg} / \mathrm{kg}$ and $300 \mathrm{mg} / \mathrm{kg}$ per oral per day till completion of 34 weeks in addition to the high fat diet. At 34 weeks all the parameters were re-estimated.
\end{abstract}

RESULTS: It was observed that both doses of glycyrrhizin significantly reduced FBSL and insulin levels in group-C $(95.00 \pm 8.23 \mathrm{mg} / \mathrm{dl}, 67 \mathrm{l} .60 \pm 55.5 \mathrm{I} \mu \mathrm{lU} / \mathrm{ml})$ and group-D $(94.00 \pm 6.27 \mathrm{mg} / \mathrm{dl}, 675.00 \pm 44.96 \mu \mathrm{lU} / \mathrm{ml})$ as compared to group-B $(236.10 \pm 13.26 \mathrm{mg} / \mathrm{dl}, 1052.80 \pm 37.82 \mu \mathrm{IU} / \mathrm{ml})[\mathrm{p}$-value $<0.00 \mathrm{I}]$ at 34 weeks. HOMA-IR decreased [group-C (I57.62 \pm 19.39$)$ and group-D $(157.03 \pm 18.21)$ vs group-B $(6 \mid 3.79 \pm 49.91)$ ] whereas HOMA- $\beta$ [group-C $(2498.23 \pm 299.58)$ and group-D $(2526.24 \pm 150.65)$ vs group-B $(1546.87 \pm 106.81)$ ] and QUICKI increased [group-C $(0.208 \pm 0.00)$ and group-D $(0.208 \pm 0.002)$ vs group-B $(0.185 \pm 0.00 \mathrm{I})$ ] (P-value $<0.001)$. Body weight decreased insignificantly in group-C $(344.00 \pm 30.21 \mathrm{mg})(P$-value $>0.05)$ but significantly in group-D $(293.20 \pm 42.54)$ as compared to group- $\mathrm{B}(372.00 \pm 24.03)[\mathrm{P}$-value $<0.001]$

CONCLUSION: Glycyrrhizin effectively improves glycaemic control in rat model of type 2 diabetes mellitus.

KEY WORDS: Glycyrrhizin (MeSH); Diabetes Mellitus (MeSH); Diabetes Mellitus, Experimental (MeSH); Blood Glucose (MeSH); Insulin (MeSH); HOMA-IR (Non$\mathrm{MeSH}) ; \mathrm{HOMA}-\beta$ (Non-MeSH); QUICKI (Non-MeSH); Glycemic Index (MeSH).

THIS ARTICLE MAY BE CITED AS: Fatimah M, Malik M, Mushtaq S, Sarfraz J, Mushtaq Z, Chiragh S. Dose dependent effect of glycyrrhizin on glycaemic control of type 2 diabetic rats. Khyber Med Univ J 2020; I2(2): 121 5. DOI: 10.35845/kmuj.2020.19819.

\section{INTRODUCTION}

$\mathrm{D}$ abetes mellitus (DM) is a common problem affecting approximately 285 million people worldwide.' Diabetes prevalence is due to over population, socioeconomic problems, sedentary life style and obesity. Type 2 diabetes involves insulin resistance (decreased sensitivity to insulin) and beta cell dysfunction (relative insulin deficiency). ${ }^{2}$

In Pakistan, the prevalence of type 2 diabetes is $16.98 \%$ and prediabetes is $10.91 \%$. $^{3}$ People when diagnosed with DM are already suffering from diabetic complications. Lack of education, poverty and late diagnosis can result in these complications. Zia A. et al showed that type 2 diabetic patients were having macrovascular complications like ischemic heart disease (28.17\%), stroke (8.45\%) \& peripheral vascular disease $(5.35 \%)$ as well as microvascular complications like retinopathy $(0.56 \%)$ and nephropathy $(0.84 \%){ }^{4}$
I. Department of Pharmacology, Post Graduate Medical Institute, Lahore, Pakistan.

2. Department of Pharmacology, Sahara Medical College, Narowal, Pakistan

3. Department of Pharmacology, Avicenna Medical \& Dental College, Lahore, Pakistan

4. Department of Pharmacology, Independent Medical College, Faisalabad, Pakistan

5. Department of Pharmacology, King Edward Medical University, Lahore, Pakistan

6. Department of Pharmacology, Sahiwal Medical College, Sahiwal, Pakistan

7. Department of Pharmacology, Al-Aleem Medical College, Lahore, Pakistan Email『: dr.mufakhara@gmail.com Contact \#: +92-321-9887990

$\begin{array}{ll}\text { Date Submitted: } & \text { October 16, 2019 } \\ \text { Date Revised: } & \text { April 02, 2020 } \\ \text { Date Accepted: } & \text { April 05, 2020 }\end{array}$

Main approaches of treatment for diabetes are diet restrictions, exercise, oral anti-hypoglycemic agents and insulin. Multiple oral drugs with hypoglycemic action are available in market nowadays however most of them have adverse effects and patients develop drug resistance. These include sulfonylureas, meglitinides, biguanides, -glucosidase inhibitors and thiazolidinediones.

Glycyrrhiza glabra (Licorice or sweet wood) is a traditional herb that germinates in different parts of the world. Traditionally, licorice has been used for the treatment of respiratory tract problems, nephrolithiasis, hepatitis C, dermatological problems, cardiovascular diseases, diabetes, gastrointestinal ulcers and gastric pain. ${ }^{6}$ Studies have reported the therapeutic effect of glycyrrhizin ${ }^{7}$ or its metabolite $18 \beta$-glycyrrhetinic acid alone ${ }^{8}$ or in comparison to glibenclamide ${ }^{9}$ in streptozotocin-induced type I diabetic rat model. Another study has shown that glycyrrhizin increases insulin sensitivity in high fat diet induced obese rats. ${ }^{10}$

As most diabetic patients show poor compliance to medical treatment due to adverse effects, hence this study was conducted to determine therapeutic effect of two different doses of glycyrrhizin in treatment of diet induced type 2 diabetic rat model over shorter duration of time. 
TABLE I: EFFECT OF GLYCYRRHIZIN ON BODY WEIGHT AND FASTING BLOOD SUGAR LEVEL OF TYPE 2 DIABETIC RATS $(\mathrm{N}=10)$

\begin{tabular}{|c|c|c|c|c|c|c|}
\hline & \multicolumn{3}{|c|}{ Body Weight (g) } & \multicolumn{3}{|c|}{ Fasting Blood Sugar Level (mg/dl) } \\
\hline & Week 32 & Week 34 & $P$ value & Week 32 & Week 34 & P value \\
\hline $\begin{array}{l}\text { Group A } \\
\text { (normal control) }\end{array}$ & $249.60 \pm 12.20$ & $258.50 \pm 11.38$ & $3<0.001$ & $84.40 \pm 6.96$ & $87.10 \pm 9.04$ & 0.081 \\
\hline $\begin{array}{l}\text { Group B } \\
\text { (diabetic control) }\end{array}$ & $355.50 \pm 25.09$ & $372.00 \pm 24.03$ & $<0.001$ & $212.00 \pm 13.97$ & $236.10 \pm 13.26$ & $<0.001$ \\
\hline $\begin{array}{l}\text { Group C } \\
\text { (glycyrrhizin I50) }\end{array}$ & $372.00 \pm 24.03$ & $344.00 \pm 30.21$ & $<0.001$ & $225.40 \pm 13.59$ & $95.00 \pm 8.23 *$ & $<0.001$ \\
\hline $\begin{array}{l}\text { Group D } \\
\text { (glycyrrhizin 300) }\end{array}$ & $385.60 \pm 33.55$ & $293.20 \pm 42.54 *$ & $*<0.001$ & $227.60 \pm 17.30$ & $94.00 \pm 6.27 *$ & $<0.001$ \\
\hline ANOVA & $<0.001$ & $<0.001$ & & $<0.001$ & $<0.001$ & \\
\hline
\end{tabular}

TABLE II: EFFECT OF GLYCYRRHIZIN ON SERUM INSULIN AND HOMA-IR OF TYPE 2 DIABETIC RATS $(\mathbf{N}=10)$

\begin{tabular}{|l|c|c|c|c|c|c|}
\hline & \multicolumn{3}{|c|}{ Serum Insulin $(\mu \mathrm{IU} / \mathrm{ML})$} & \multicolumn{3}{c|}{ HOMA-IR } \\
\cline { 2 - 7 } & Week 32 & Week 34 & P value & Week 32 & Week 34 & P value \\
\hline $\begin{array}{l}\text { Group A } \\
\text { (normal control) }\end{array}$ & $628.60 \pm 74.18$ & $670.00 \pm 52.27$ & 0.089 & $131.65 \pm 23.38$ & $144.30 \pm 20.75$ & 0.049 \\
\hline $\begin{array}{l}\text { Group B } \\
\text { (diabetic control) }\end{array}$ & $917.60 \pm 39.58$ & $1052.80 \pm 37.82$ & $<0.00 I$ & $479.79 \pm 28.74$ & $613.79 \pm 49.91$ & $<0.00 I$ \\
\hline $\begin{array}{l}\text { Group C } \\
\text { (glycyrrhizin I50) }\end{array}$ & $848.90 \pm 73.42$ & $671.60 \pm 55.51 *$ & $<0.001$ & $472.73 \pm 52.30$ & $157.62 \pm 19.39 *$ & $<0.001$ \\
\hline $\begin{array}{l}\text { Group D } \\
\text { (glycyrrhizin 300) }\end{array}$ & $868.60 \pm 53.08$ & $675.00 \pm 44.96 *$ & $<0.001$ & $488.22 \pm 49.43$ & $157.03 \pm 18.21 *$ & $<0.00 I$ \\
\hline ANOVA & $<0.00 I$ & $<0.00 I$ & & $<0.00 I$ & $<0.00 I$ & \\
\hline
\end{tabular}

TABLE III: EFFECT OF GLYCYRRHIZIN ON HOMA-B AND QUICKI OF TYPE 2 DIABETIC RATS $(\mathrm{N}=10)$

\begin{tabular}{|c|c|c|c|c|c|c|}
\hline & \multicolumn{3}{|c|}{ HOMA- $\beta^{\#}$} & \multicolumn{3}{|c|}{ QUICKI $^{\text {s }}$} \\
\hline & Week 32 & Week 34 & $P$ value & Week 32 & Week 34 & P value \\
\hline $\begin{array}{l}\text { Group A } \\
\text { (normal control) }\end{array}$ & $2621.83 \pm 273.37$ & $2730.03 \pm 335.58$ & 0.275 & $0.211 \pm 0.003$ & $0.210 \pm 0.002$ & 0.041 \\
\hline $\begin{array}{l}\text { Group B } \\
\text { (diabetic control) }\end{array}$ & $1502.75 \pm 140.96$ & $1546.87 \pm 106.81$ & 0.171 & $0.189 \pm 0.001$ & $0.185 \pm 0.001$ & $<0.001$ \\
\hline $\begin{array}{l}\text { Group C } \\
\text { (glycyrrhizin I50) }\end{array}$ & $1296.58 \pm 137.70$ & $2498.23 \pm 299.58 *$ & $<0.001$ & $0.189 \pm 0.001$ & $0.208 \pm 0.00 *$ & $<0.001$ \\
\hline $\begin{array}{l}\text { Group D } \\
\text { (glycyrrhizin 300) }\end{array}$ & $1318.40 \pm 137.07$ & $2526.24 \pm 150.65 *$ & $<0.001$ & $0.188 \pm 0.001$ & $0.208 \pm 0.002 *$ & $<0.001$ \\
\hline ANOVA & $<0.001$ & $<0.001$ & & $<0.001$ & $<0.001$ & \\
\hline
\end{tabular}

\section{METHODS}

This was an experimental study conducted at Post-Graduate Medical Institute (PGMI), Lahore after approval from institutional ethical committee. Duration of intervention was 34 weeks. Sample size was calculated by taking mean \pm SD of fasting blood sugar level (FBSL) of diabetic control and glycyrrhizin treated rats" using formula for calculation of two independent samples at $90 \%$ power of study and $5 \%$ level of significance. Simple random sampling using balloting method was used for division of rats into 4 groups (A-D). Sample size calculated was six animals in each group but considering the number of animals in similar studies, it was decided to take 10 animals in each group. Taking into account mortality during long study period and failure of induction of diabetes, initially 18 rats were taken in each group. Sprague Dawley rats were selected as an experimental animal as they share many anatomical and physiological similarities with humans along with similar metabolic pathway, ease of breeding, cost effectiveness and availability of large data base. ${ }^{12}$ Sprague- Dawley rats, 3 weeks old were initially selected. At 32 weeks, rats developing diabetes (FBSL $>126 \mathrm{mg} / \mathrm{dl}$ ) were included in the study. Any rat with any significant sign of disease was excluded. ELISA Kit for serum insulin (Glory Science Ltd., USA), Glucose Oxidase Kit (Randox, UK), Glycyrrhizin (Creative Diagnostics, USA), Injection Dexamethasone (MSD, UK) and Glucometer with strips (Accu-Chek Performa $\left.{ }^{\circledR}\right)$ were used as testing materials. Beef fat and normal rat chow was purchased from Tollinton market whereas sucrose was purchased from general grocery store. Rats were bought from University of Health Sciences, Lahore and kept in the animal house facility of PGMI, Lahore in specialized iron cages. Room temperature was set at $25 \pm 2^{\circ} \mathrm{C}$ and hygienic environment was maintained. They were provided free access to rat chow and water and one week was provided to them for acclimatization.

After acclimatization (4 weeks of age) rats in Group A received normal rat chow whereas rats in Group B, C and D were fed on high fat and sucrose diet which was composed of $30 \%$ of beef fat, $10 \%$ of sucrose and $60 \%$ of normal rat chow. ${ }^{13}$ After 30 weeks of high fat feeding, inj. dexamethasone $0.25 \mathrm{mg} / \mathrm{kg} /$ day was given subcutaneously for two weeks along with high fat diet. At 32 weeks rats with FBSL > $126 \mathrm{mg} / \mathrm{dl}$ were considered as diabetic ${ }^{14}$ and included in the study.

Rats were divided into four experimental groups named as normal control (Group A), diabetic control (Group B), glycyrrhizin 150 (Group C) and glycyrrhizin 300 (Group D) respectively. Group A was given normal diet throughout the study period. At 32 weeks distilled water $3 \mathrm{ml} / \mathrm{kg}$ was given by oral route daily as a single morning dose for next 2 weeks. Group B, C and D received high fat diet throughout the study period. At 30 weeks, high fat diet plus injection $\mathrm{dexameth}$ asone $0.25 \mathrm{mg} / \mathrm{kg}$ subcutaneously once daily was given. ${ }^{15} \mathrm{At}$ 32 weeks, Group B received distilled water $3 \mathrm{ml} / \mathrm{kg}$, Group C received glycyrrhizin $150 \mathrm{mg} / 3 \mathrm{ml} / \mathrm{kg}$ and Group D received glycyrrhizin $300 \mathrm{mg} / 3 \mathrm{ml} / \mathrm{kg}$ respectively by oral route daily as a single morning dose. 
Blood glucose was measured every week after overnight fasting of 12 hours using a glucometer. Blood was taken from tail vein. At 32 and 34 weeks, blood samples were taken by cardiac puncture, after 12 hour overnight fast. Blood was coagulated at room temperature for 10-20 min. Samples were centrifuged for 20 minutes at room temperature at a speed of 2000 3000 revolutions per minute. Serum was then separated and stored at $-20^{\circ} \mathrm{C}$. This serum was used for estimation of fasting blood sugar level by glucose oxidase method and serum insulin level by enzyme linked immunosorbent assay (ELISA) kit.

Body weight was measured using analytical balance weekly. Figure I shows the body weight of animals in four groups over period of experiment.

Homeostatic Model Assessment of Insulin Resistance (HOMA-IR) and Homeostatic Model Assessment of beta cells (HOMA$\beta$ ) were calculated with values of FBSL and fasting serum insulin using formulae by Song. ${ }^{16}$ Quantitative insulin sensitivity check index (QUICKI) was calculated taking log of FBSL and fasting serum insulin using formula by Yokoyama. ${ }^{17}$

SPSS 23 was used to enter and analyze data. Quantitative variables like body weight, fasting blood sugar level, insulin, HOMA-IR, HOMA- $\beta$, QUICKI were given as Mean \pm SD. Comparison between groups was done by One way ANOVA. Graph pad prism version 6 was used to develop bar diagrams and line graphs to exhibit the difference between four groups and values trends. To observe which group mean differs, Post hoc Tukey's test was applied. To analyze the difference within a group, t-test was applied. P-value of $\leq 0.05$ was considered as significant.

\section{RESULTS}

Initially 72 rats were taken and those were grouped into 4 groups. During acclimatization, two rats in normal control and one in each high fat diet group died. At 32 weeks, 12 rats in group $B$ and 10 rats each in group $C$ and $D$ became diabetic. For statistical analysis, 10 rats were included in each group.

Body weight as measured every week is shown in Figure I. As shown in Table I, in group $A$ and $B$, body weight increased significantly while both in group $C$ and $D$, body weight decreased and this decrease was highly significant. Comparison between groups at 32 and 34 weeks by ANOVA revealed significant difference. Difference between group $C$ and $D$ at 34 week was insignificant.

Fasting blood sugar level increased in groups taking high fat diet but not in the diabetic range upto 30 weeks. After inj. dexamethasone, most of the rats became diabetic at 34 weeks. Mean \pm SD of fasting blood sugar levels at 32 and 34 week as measured by oxidase method are given in Table I. As shown in Table I, in group A, blood sugar level increased insignificantly. In group B, blood sugar level increased significantly while both in group $C$ and $D$, level decreased and this decrease was highly significant. Comparison between groups at 32 and 34 weeks by ANOVA revealed significant difference. Difference between group $C$ and $D$ at 34 week was insignificant.

As shown in Table II, in group A, serum insulin level increased insignificantly. In group $B$, serum insulin level increased significantly while both in group $C$ and $D$, level decreased and this decrease was highly significant. Comparison between groups at 32 and 34 weeks by ANOVA revealed significant difference. Difference between group $C$ and $D$ at 34 week was insignificant.

As shown in Table II, in group A, the increase in HOMA IR was marginally significant. In group B, HOMA IR value increased highly significantly while both in groups $C$ and $D$, value decreased and this decrease was highly significant. Comparison between groups at 32 and 34 weeks by ANOVA revealed significant difference. Difference between group C and $D$ at 34 week was insignificant.

As shown in Table III, in group A, HOMA- $\beta$ value increased insignificantly. In group $B$,
HOMA- $\beta$ value increased insignificantly while both in Group C and D, value increased and this increase was highly significant. Comparison between groups at 32 and 34 weeks by ANOVA revealed significant difference. Difference between group C and D at 34 week was insignificant.

As shown in Table III, in group A, QUICKI value decreased. In group $B$, QUICKI value decreased highly significantly while both in group $C$ and $D$, it increased and this increase was highly significant. Comparison between groups at 32 and 34 weeks by ANOVA revealed significant difference. Difference between group C and $D$ at 34 week was insignificant.

\section{DISCUSSION}

This study was conducted to see the dose dependent effect of glycyrrhizin on type 2 diabetes mellitus in a rat model. Previously effect of glycyrrhizin was studied on type 2 diabetes models which were induced chemically or genetically. At present, type 2 diabetes is caused mainly by sedentary life style and unhealthy dietary changes hence our model was diet induced to resemble closely to type 2 diabetes mellitus which is prevalent nowadays.

It was deduced from the results that glycyrrhizin in both doses of $150 \mathrm{mg}$ and $300 \mathrm{mg}$ is beneficial in lowering BSL. Both doses of glycyrrhizin were effective in decreasing insulin resistance and increasing beta cell function. However, no significant difference among the results of the two doses of glycyrrhizin was observed on most of parameters but higher dose $(300 \mathrm{mg} / \mathrm{kg})$ was more effective in lowering body weight.

In the present study, body weight of both

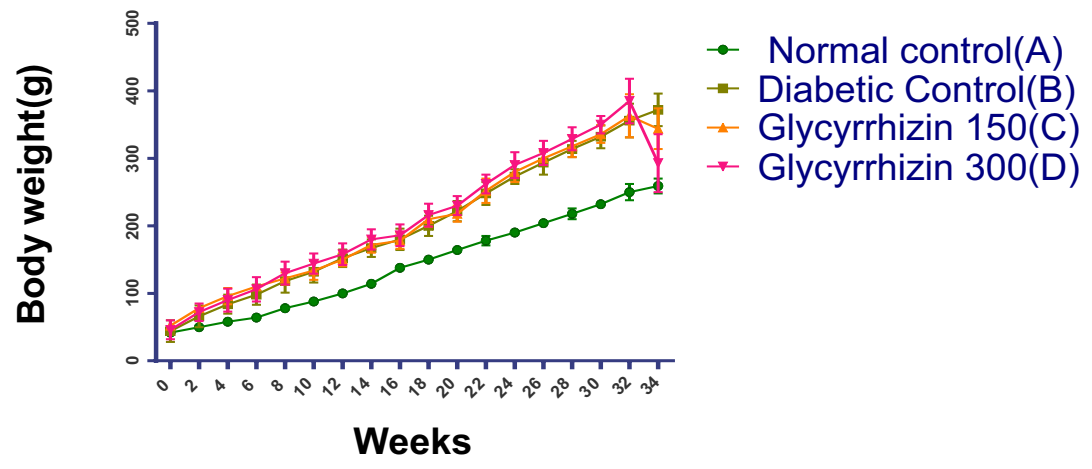

Figure I: Body weight (grams) of animals in four groups over period of experiment 
experimental groups receiving $150 \mathrm{mg}$ glycyrrhizin and $300 \mathrm{mg}$ glycyrrhizin decreased with $p$ value $<0.00$ I each. This is similar to human study in which they gave 3.5 gram licorice per day to 15 individuals for 2 months and found that their body fat mass decreased significantly with p value $<0.02$. $^{18}$

Fasting BSL decreased significantly in both experimental groups with $p$ value $<0.001$ each. This is similar to the studies where fasting BSL was significantly reduced by herbal mixture containing glycyrrhizin $300 \mathrm{mg} / \mathrm{kg}$ in high fat diet induced obese rats with $\mathrm{p}$ value $<0.05 .^{19}$ In another study, $50 \mathrm{mg} / \mathrm{kg}$ intra-peritoneal administration of glycyrrhizin for one week exhibited the similar reduction in BSL of fructose induced type 2 diabetic rats with $p$ value $<0.01{ }^{20}$

Fasting insulin deceased significantly by both doses glycyrrhizin in experimental groups with $p$ value $<0.00$ I each. This is similar to study in which $100 \mathrm{mg} / \mathrm{kg}$ of glycyrrhizic acid was administered per orally to high fat diet induced obese rats for 28 days and it was found that serum insulin decreased with $p$ value $<0.05 .^{10}$ Similar results were found by administrating $50 \mathrm{mg} / \mathrm{kg}$ of glycyrrhizin intraperitoneally for one week with $p$ value $<0.0$ I. $^{20}$

HOMA-IR represents the level of insulin resistance produced by hyperglycemia. It shows good correlation to glycemic clamp." When HOMA-IR was estimated, it was found to be significantly decreased by $150 \mathrm{mg}$ and $300 \mathrm{mg}$ of glycyrrhizin. Comparable results were found by study done on type 2 diabetic rats by giving glycyrrhizin $100 \mathrm{mg} / \mathrm{kg}$ for 24 hours per orally with $p$ value of $<0.05$. $^{22}$ Intraperitoneal administration of glycyrrhizin $50 \mathrm{mg} / \mathrm{kg}$ for one week on male Wistar rats in another study showed the similar results. ${ }^{20}$ Chinese poly herbal formula containing glycyrrhizin given for 60 days to Wistar rats ${ }^{23}$ decreased HOMA-IR with $p$ value $<0.0$ land this is comparable with the use of both doses of glycyrrhizin in our experimental groups with $\mathrm{P}$ value $<0.00$ I each.

HOMA- $\beta$ represents the beta cell function. Low HOMA- $\beta$ value shows increase prevalence of type 2 diabetes. ${ }^{16}$ In our study, on estimation of HOMA- $\beta$, it was found that both doses of glycyrrhizin increased beta cell function significantly with $p$ value $<0.00$ I each. Jiang Tang Fang Long Formula given at $30 \mathrm{~g} / \mathrm{kg} / \mathrm{d}$ for 60 days $^{23}$ increased HOMA- $\beta$ with p value $<$ 0.01 .

QUICKI (quantitative insulin sensitivity check index) is simple and genuine method to determine insulin sensitivity by using fasting glucose and fasting insulin. ${ }^{24}$ Higher the QUICKI, higher the insulin sensitivity and lower the risk of diabetes mellitus. On estimating QUICKI, it was found to be increased significantly in both experimental groups as compared to diabetic control with $p$ value $<0.001$ each.

Probable mechanism in improvement of insulin resistance is by increasing expression of GLUT 4 and PPARY. ${ }^{27}$

Limitations of the study are as under:

- Mechanism of action of glycyrrhizin was not determined by us due to lack of facility and we took the reference from another article.

- Glycyrrhizin increases blood pressure but we used the dose which does not increase blood pressure. It was desirable to check blood pressure but because of lack of facility, it was not done.

\section{CONCLUSION AND RECOMMENDATIONS}

It was observed that both doses of glycyrrhizin i.e. $150 \mathrm{mg}$ and $300 \mathrm{mg}$ significantly reduced fasting blood sugar level and serum insulin. HOMA IR decreased whereas HOMA- $\beta$ and QUICKI increased. Body weight decreased insignificantly by glycyrrhizin $150 \mathrm{mg} / \mathrm{kg}$ but significantly with glycyrrhizin $300 \mathrm{mg} / \mathrm{kg}$.

It is concluded that glycyrrhizin has antihyperglycemic effect in diet induced type 2 diabetic rat model which is not dose dependent and smaller doses are recommended for future studies. In future, the role of glycyrrhizin can also be assessed for prevention of type 2 diabetes.

\section{REFERENCES}

I. Lardizabal JA, Deedwani PC. The role of renin-angiotensin agents in altering the natural history of type 2 diabetes mellitus. Curr Cardiol Rep 20I0;12(6):464-7I. DOI: 10.1007 /s I I886-010-0138-।.

2. Zaccardi F, Webb DR, Yates T, Davies MJ. Pathophysiology of type I and type
2 diabetes mellitus: a 90-year perspective. Postgrad Med J 2016. 92(1084):63-9. DOI: I0.1।36 /postgradmedj-20I5-I3328I.

3. Aamir AH, UI-Haq Z, Mahar SA, Qureshi FM, Ahmad I, Jawa A, et al. Diabetes Prevalence Survey of Pakistan (DPS-PAK): prevalence of type 2 diabetes mellitus and prediabetes using HbAlc: a population-based survey from Pakistan. BMJ Open 2019;9:e025300. DOI: I0.II36/ bmjopen-20I8025300.

4. Zia A, Bhatti A, Jalil F, Wang X, John P, Kiani AK, et al. Prevalence of type 2 diabetes-associated complications in Pakistan. Int J Diabetes Dev Ctries 2016;36(2): 179-88. DOI: 10.1007/s |34|0-0|5-0380-6.

5. Martha SNK, Umesh M. Pancreatic hormones and antidiabetic drugs. In: Bertam GK, Anthony JT (eds). Basic and clinical pharmacology. $13^{\text {th }}$ ed. McGraw Hill Education (India); 2013.pp.723-46.

6. Marjan NA, Hossein H. Review of pharmacological effects of Glycyrrhiza sp. and its bioactive compounds. Phytother Res 2008; 22(6): 709-24. DOI: $10.1002 /$ ptr.2362.

7. Sen S, Roy M, Chakraborti AS. Ameliorative effect of glycyrrhizin on streptozotocin-induced diabetes in rats. J Pharm Pharmacol 20I I;63(2):287-96. DOI: I0.1III/ j.2042-7158.2010.01217.x.

8. Kalaiarasi P, Pugalendi KV. Protective effect of 18b-glycyrrhetinic acid on lipid peroxidation and antioxidant enzymes in experimental diabetes. J Pharm Res 201 I;4(1):107-1 I.

9. Kalaiarasi P, Kaviarasan K, Pugalendi KV. Hypolipidemic activity of $18 \beta$ glycyrrhetinic acid on streptozotocininduced diabetic rats. Eur J Pharmaco 2009;6/2(I-3):93-7. DOI: 10.1016/ j.ejphar.2009.04.003.

I0. Eu CH, Lim WY, Ton SH, Kadir KA. Glycyrrhizic acid improved lipoprotein lipase expression, insulin sensitivity, serum lipid and lipid deposition in high-fat diet-induced obese rats. Lipids Health Dis 2010;9:8I. DOI: 10.1I86/14765||$X-9-8 \mid$.

II. Takii H, Kometani T, Nishimura T, Nakae T, Okada S, Fushiki T. Antidiabetic effect of glycyrrhizin in 
genetically diabetic KK- Ay mice. Biol Pharm Bull 200I;24(5):484-7. DOI: 10.1248/bpb.24.484.

12. Kacew S, Festing MF. Role of rat strain in the differential sensitivity to pharmaceutical agents and naturally occurring substances. J Toxicol Environ Health 1996;47(I): I-30. DOI: $10.1080 / 009841096161960-$ 2840.

13. Shad M, Zaheer Z, Kausar S, Chiragh S. Comparative effects of losartan and pioglitazone on insulin resistance in rats. Biomedica 20 I4;30(3): I-5.

14. Jung J Y, Lim Y, Moon MS, Kim JY, Kwon O. Onion peel extracts ameliorate hyperglycemia and insulin resistance in high fat diet/streptozotocininduced diabetic rats. Nutr Metab (Lond) $2011 ; 8(1): 18$. DOI: 10.1 I86/ |743-7075-8-18.

I5. Sivabalan S, Renuka S, Menon P. Fat feeding potentiates the diabetogenic effect of dexamethasone in wistar rats. Int Arch Med 2008; I(I):7. DOI: 10.1 I 86/I 755-7682-I-7.

16. Song Y, Manson JE, Tinker L, Howard BV, Kuller LH, Nathan L, et al. Insulin sensitivity and insulin secretion determined by homeostasis model assessment (HOMA) and risk of diabetes in a multiethnic cohort of women: The women's health initiative observational study. Diabetes Care 2007;30(7):I74752. DOI: I0. 2337/dc07-0358.

17. Yokoyama H, Emoto M, Fujiwara S, Motoyama K, Morioka T, Komatsu M, et al. Quantitative insulin sensitivity check index and the reciprocal index of homeostasis model assessment are useful indexes of insulin resistance in type 2 diabetic patients with wide range of fasting plasma glucose. J Clin Endocrinol Metab 2004;89(3): 1481|484. DOI: 10.12 I0/jc.2003-03 374.

18. Armanini D, De Palo CB, Mattarello MJ, Spinella P, Zaccaria M, Ermolao A, et al. Effect of licorice on the reduction of body fat mass in healthy subjects. J Endocrinol Invest 2003;26(7):646-50. DOI: $10.1007 / B F 03347023$.

19. Amin A, Nagy M. Effect of Carnitine and herbal mixture extract on obesity induced by high fat diet in rats. Diabetol Metab Syndr 2009; I(I): 17. DOI: I0.I I86/I7585996-I-I7.

20. Sil R, Ray D, Chakraborti AS. Glycyrrhizin ameliorates insulin resistance, hyperglycemia, dyslipidemia and oxidative stress in fructose- induced metabolic syndrome-X in rat model. Ind J Exp
Biol 20I 3;5 I (2): I29-38.

21. Salgado AL, Carvalho LD, Oliveira AC, Santos VN, Vieira JG, Parise ER. Insulin resistance index (HOMA-IR) in the differentiation of patients with nonalcoholic fatty liver disease and healthy individuals. Arq Gastroenterol 20I0;47(2):165-9. DOI: 10.1590/s 0004-280320 I0000200009.

22. Yin CY, Ha TS, Kadir KA. Effects of glycyrrhizic acid on peroxisome proliferator-activated receptor gamma (PPARy), lipoprotein lipase (LPL) serum lipid and HOMA-IR in rats. PPAR Res 2010;2010:530265. DOI: 10.1155/2010/530265.

23. YunXia Y, Ruiyu L, Mei JJ, Yanzhuo Z, Meng $L$, Bin L, et al. Effects of jiang Tang Fang Long Formula on insulin production and function in an animal model of diabetic hearing loss. J Otology 2013;8(2):88-90. DOI: 10 . 1016/SI672-2930(I3)500I8-3.

24. Katz A, Nambi SS, Mather K, Baron $A D$, Follmann DA, Sullivan $G$, et al. Quantitative insulin sensitivity check index: a simple, accurate method for assessing insulin sensitivity in humans. J Clin Endocrinol Metab 2000;85(7):2402-I0. DOI: I0.12I0 /jcem.85.7.666I.

\section{AUTHORS' CONTRIBUTIONS}

Following authors have made substantial contributions to the manuscript as under:

MF: Conception and study design, acquisition of data, drafting the manuscript, final approval of the version to be published

MM: Analysis and interpretation of data, drafting the manuscript, final approval of the version to be published

SM \& ZM: Acquisition, analysis and interpretation of data, drafting the manuscript, critical review, final approval of the version to be published.

JS: Acquisition, analysis and interpretation of data, drafting the manuscript, final approval of the version to be published.

SC: Study design, critical review, final approval of the version to be published.

Authors agree to be accountable for all aspects of the work in ensuring that questions related to the accuracy or integrity of any part of the work are appropriately investigated and resolved.

CONFLICT OF INTEREST
Authors declared no conflict of interest
GRANT SUPPORT AND FINANCIAL DISCLOSURE
NIL

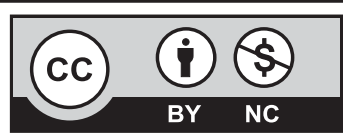

This is an Open Access article distributed under the terms of the Creative Commons Attribution-Non Commercial 2.0 Generic License. 